\title{
DAMPAK PEMBERANTASAN KORUPSI TERHADAP PEREKONOMIAN, EMISI KARBON DAN SEKTOR KEHUTANAN INDONESIA (Corruption Eradication Impacts on The Economy, Carbon Emissions and Forestry Sector in Indonesia)
}

\author{
Sigit Andy Cahyono ${ }^{1,2 *}$, Sofyan Partidjo Warsito ${ }^{3}$, Wahyu Andayani ${ }^{3}$ dan \\ Dwidjono Hadi Darwanto ${ }^{4}$ \\ ${ }^{1}$ Program Doktor, Program Studi Ilmu Kehutanan, Fakultas Kehutanan, Universitas Gadjah Mada, \\ Jl. Agro No 1 Bulaksumur, Yogyakarta, 55281. \\ ${ }^{2}$ Balai Penelitian Teknologi Kehutanan Pengelolaan Daerah Aliran Sungai, \\ Jl. Jend. A. Yani Pabelan Kartasura PO Box 295 Surakarta, 57102. \\ ${ }^{3}$ Fakultas Kehutanan, Universitas Gadjah Mada, Jl. Agro No 1 Bulaksumur, Yogyakarta, 55281. \\ ${ }^{4}$ Fakultas Pertanian, Universitas Gadjah Mada, Jl. Agro No 1 Bulaksumur, Yogyakarta, 55281.
}

*Penulis korespondensi. Tel: 08151893245. Email: sandycahyono@yahoo.com.

Diterima: 21 Januari 2015

Disetujui: 12 Juni 2015

\begin{abstract}
Abstrak
Permasalahan lingkungan, korupsi, dan perubahan iklim menjadi persoalan dunia yang tidak dapat dipisahkan dari masalah politik, moral, budaya, kelembagaan, dan ekonomi. Beberapa kajian menunjukkan korupsi akan menurunkan pertumbuhan ekonomi sedangkan kajian lainnya menunjukkan sebaliknya. Penelitian ini bertujuan mengetahui dampak pemberantasan korupsi terhadap perekonomian, emisi karbon (lingkungan) dan sektor kehutanan di Indonesia. Penelitian ini menggunakan analisis ekonometrika persamaan simultan dinamis dengan data tahun 1969-2012. Metode pendugaan model menggunakan Two Stage Least Squares (2SLS). Hasil penelitian menunjukkan bahwa keberhasilan pemberantasan korupsi akan meningkatkan investasi, pertumbuhan ekonomi, pajak, dan menurunkan pengangguran, namun tidak berdampak pada kemiskinan. Pemberantasan korupsi meningkatkan aktivitas ekonomi sehingga emisi karbon meningkat. Sektor kehutanan dapat berperan menurunkan emisi karbon dan diuntungkan dengan pemberantasan korupsi meskipun kinerja industri kehutanan dan dana reboisasi sedikit turun.
\end{abstract}

Kata kunci: emisi karbon, korupsi, lingkungan, persamaan simultan, sektor kehutanan.

\begin{abstract}
Environment problem, corruption and climate change have become the world issues that cannot be separated from political, moral, cultural, institutional, and economic problems. Several studies have pointed out that corruption lowered the economic growth while other studies suggested the opposite. This study aims to determine the impacts of corruption eradication on the economy, carbon emissions (environment) and forestry sector in Indonesia. This study used an econometric analysis of dynamic simultaneous equation based on the time series data spanned from the year of 1969 to 2012. The estimation model was performed by using Two Stage Least Squares (2SLS) method. The results indicated that the successful of corruption eradication will both increase investment, economic growth, and taxes, as well as reduce unemployment, but it had no impact on poverty alleviation. Corruption eradication increased economic activities that result in a rising of carbon emissions. The forestry sector can contribute to reduce carbon emissions and benefit from the eradication of corruption even though the performance of forestry industries and reforestation funds will be slightly decreased.
\end{abstract}

Keywords: corruption, carbon emissions, environment, forestry sector, simultaneous equations.

\section{PENDAHULUAN}

Permasalahan lingkungan, korupsi dan perubahan iklim menjadi persoalan dunia yang tidak dapat dipisahkan dari masalah politik, moral, budaya, kelembagaan, dan ekonomi (Dreher dkk, 2007; Vazquez dkk, 2007; Aidt, 2009; Goel dan Nelson, 2010; Bloom, 2010; Leitao, 2010; Pellegrini, 2011; Sims dkk, 2012; Shafiq, 2015).
Lee dkk (2015) menyimpulkan bahwa korupsi merupakan masalah serius dalam pengelolaan lingkungan. Penelitian korupsi semakin meningkat sebagai hasil beberapa faktor yaitu konsekuensi negatif korupsi di negara miskin, ketersediaan dan keterbukaan data yang lebih baik, dan isu korupsi menjadi fenomena global (Ackerman, 2006).

Banyak studi (Tanzi dan Davoodi, 1997; Mauro, 1998; Ackerman, 2006; Lambsdorff, 2007) 
menemukan bahwa korupsi menurunkan pertumbuhan ekonomi. Namun temuan Rock dan Bonnet (2004) menunjukkan hal berbeda di Asia Timur dimana korupsi meningkatkan pertumbuhan ekonomi. Korupsi dan penyuapan dapat menghindarkan perusahaan dari sulitnya peraturan birokrasi dan pelayanan yang lebih baik serta menguntungkan perusahaan karena birokrasi lebih cepat melayani kepentingan perusahaan. Vial dan Hanoteau (2010) menemukan hal yang sama dan menyebutnya sebagai "meminyaki roda pembangunan”.

Selain korupsi, kerusakan lingkungan akibat perubahan iklim yang disebabkan oleh perubahan emisi karbon juga merupakan persoalan serius yang dihadapi dunia. Korupsi memperparah perubahan iklim dan kerusakan lingkungan dimana sejumlah penelitian menunjukkan bahwa korupsi menurunkan kekuatan peraturan lingkungan (Bhattacharyya dan Hodler, 2010; Walter, 2013; Sundstrom, 2015), sehingga degradasi lingkungan dan emisi karbon cenderung meningkat dengan meningkatnya korupsi.

Salah satu hal penting dalam perubahan emisi karbon dan korupsi adalah perubahan lahan hutan. Sejumlah studi menunjukkan bahwa aktivitas lobi di negara berkembang memainkan peran signifikan dalam mempengaruhi keputusan pemerintah untuk menentukan perubahan penggunaan lahan hutan dan konsesi hutan (Barbier dkk, 2005; Amacher dkk, 2012; Sloan, 2014; Halkos dan Tzeremes, 2014). Kegiatan lobi memberi peluang bagi penggambil keputusan untuk mencari untung (rent seeking) dengan korupsi dan penyuapan oleh pelobi (Umar, 2011). Korupsi dan penyuapan memperlancar perubahan penggunaan lahan hutan sehingga meningkatkan emisi karbon dan menurunkan kemampuan hutan menyerap karbon dari atmosfer.

Untuk kasus Indonesia, Dermawan dkk (2011) berpendapat bahwa kekayaan hutan Indonesia dengan berbagai kepentingannya sangat rawan korupsi. Pertama, proyek besar dengan biaya ataupun menghasilkan pendapatan besar berada di sektor kehutanan. Kedua, konsesi dan izin pemanfaatan hutan dan alih fungsi menawarkan pendapatan yang besar, misal penyalahgunaan Dana Reboisasi dan izin alih fungsi lahan. Ketiga, pembalakan liar dan korupsi yang terkait dengannya. Selain itu, REDD (Reducing emission from deforestastion dan degradation) juga membuka peluang korupsi yang besar terkait kegiatan REDD dan pembayaran imbal jasa keberhasilan REDD. Korupsi juga dapat terjadi pada kebijakan, perizinan, pembagian manfaat, proyek yang tidak menghasilkan penurunan emisi karbon, pelaporan pengurangan emisi palsu, perhitungan ganda, manipulasi tingkat acuan, dan sebagainya yang menguntungkan satu pihak tertentu.

Berdasarkan uraian tersebut, cukup banyak penelitian tentang masalah korupsi, perubahan klim dan kehutanan, tetapi masih langka yang mengkaitkan semuanya dalam sebuah sistem perekonomian suatu negara. Langka pula penelitian tentang dampak korupsi terhadap ekonomi, emisi karbon (lingkungan) dan kehutanan secara simultan. Sehubungan dengan itu penelitian ini bertujuan mengetahui dampak pemberantasan korupsi terhadap perekonomian, emisi karbon dan sektor kehutanan. Diharapkan penelitian ini dapat menambah wawasan, memberi informasi lanjut dan menjadi tantangan bagi desain kebijakan kehutanan (Amacher, 2006) di Indonesia.

\section{METODE PENELITIAN}

\section{Data dan Sumber Data}

Data yang digunakan merupakan data deret waktu 1969-2012. Beberapa sumber data yang dirujuk antara lain: Badan Pusat Statistik, Bank Indonesia, Departemen Kehutanan, Departemen Pertanian, Departemen Perdagangan, FAO, Departemen ESDM, World Bank, Departemen Keuangan, Wetland International, IPCCC, Transparency International, CIFOR/ ICRAF, dan publikasi penelitian yang relevan.

Pengukuran tingkat korupsi relatif sulit dilakukan. Beberapa lembaga telah berupaya melakukan pengukuran tingkat korupsi antara lain (Andrei dkk, 2009): ukuran tingkat korupsi International Country Risk Guide (ICRG), Corruption Perception Index (CPI) oleh Transparancy International (TI) dan index Corruption Control (CC). Banyak estimasi korupsi didasarkan pada survey persepsi dibandingkan dengan mengukur korupsi secara langsung (Olken dan Pande, 2012; Varvarigos dan Arsenis, 2015). Pada penelitian ini dipergunakan hasil pengukuran tingkat korupsi dari Transparency International.

\section{Alat Analisis}

Berbeda dengan penelitian korupsi lainnya yang umumnya menggunakan regresi persamaan tunggal. Penelitian ini menggunakan model ekonometrik yang terdiri dari 8 blok yaitu permintaan agregat, perdagangan, moneter, fiskal, pengangguran kemiskinan, emisi karbon dan konsumsi energi, sektor kehutanan (pasar kayu) dan deforestasi, dan sektoral (output, tenaga kerja dan pendapatan). 
Pendugaan model ekonomi menggunakan metode Two Stage Least Squares (2SLS), karena metode ini cukup toleran terhadap kesalahan spesifikasi model sehingga kesalahan spesifikasi satu persamaan tidak ditransfer ke persamaan lain. Pengaruh secara bersama-sama dari peubah penjelas dari setiap persamaan dalam model di uji menggunakan uji $\mathrm{F}$, dan pengaruh individual peubah penjelasnya diuji menggunakan uji t. Uji statistic Durbin Watson dan Durbin h dipergunakan untuk mengetahui korelasi serial dalam setiap persamaan di model. Proses perhitungan penduga parameter persamaan dilakukan menggunakan program komputer SAS/ETS (Statistical Analysis System Econometric Time Series) versi 9.12.

Hasil estimasi model selanjutnya dilakukan validasi model yang bertujuan mengetahui tingkat representasi model dibandingkan dengan dunia nyata sebagai dasar untuk melakukan simulasi. Instrumen yang dipergunakan untuk mengukur validasi model adalah koefisien determinasi $\left(\mathrm{R}^{2}\right)$, Root Mean Square (RMSE) dan Root Mean Square Percented Error (RMSPE) dan U-Theil. Model yang baik memiliki nilai $\mathrm{R}^{2}$ yang besar tetapi nilai RMSE, RMSPE, dan U-Theilnya semakin kecil.

\section{Simulasi Kebijakan}

Untuk mengetahui besarnya dampak pemberantasan korupsi terhadap perekonomian, perubahan iklim dan sektor kehutanan dilakukan dengan simulasi model. Pada dasarnya simulasi model bertujuan: untuk melakukan pengujian dan evaluasi terhadap model, mengevaluasi kebijakan pada masa lalu atau yang terjadi, dan untuk peramalan masa depan. Salah satu indikator keberhasilan pemberantasan korupsi adalah peningkatan indeks persepsi korupsi. Oleh karena itu, penelitian ini mensimulasikan dampak pencapaian indeks persepsi korupsi sebesar 5 dan 7 yang merupakan target Rencana Pembangunan Nasional. Selanjutnya hasil simulasi dibandingkan dengan simulasi dasarnya sehingga diperoleh besarnya dampak dari pemberantasan korupsi.

\section{HASIL DAN PEMBAHASAN}

\section{Pemberantasan Korupsi di Indonesia}

Pemberantasan korupsi di Indonesia sudah berlangsung sejak tahun 1950-an. Dimulai saat abuse of power menteri ekonomi Iskak Tjokroadisuryo (kabinet Ali Sastroamidjojo I) berupa pemberian lisensi impor dari Politik Benteng ke teman-temanya yang kemudian dijual ke pengusaha Cina (program Ali-Baba).

Secara yuridis, Indonesia sejak tahun 1960 telah melakukan upaya pemberantasan korupsi dengan Perpu No 24 tahun 1960 tentang Pengusutan, Penuntutan dan Pemeriksaan Tindak Pidana Korupsi. Kemudian pada tahun 1971 diterbitkan UU No 3 tahun 1971 tentang Tindak Pidana Korupsi yang pada tahun 1999 diganti dengan UU No 31 tahun 1999 tentang Pemberantasan Tindak Pidana Korupsi junto UU No 20 Tahun 2001 tentang Tindak Pidana Korupsi. Selanjutnya pada tahun 2002 dikeluarkan UU No 30 tahun 2002 tentang Komisi Pemberantasan Korupsi dan UU No 15 tahun 2002 tentang Tindak Pencucian Uang. Pada tahun 2006 pemerintah meratifikasi konvensi internasional tentang anti korupsi melalui UU No 7 tahun 2006 tentang Pengesahan United Nations Convention Againts Corruption 2003. Peraturan perundangan tersebut menunjukkan komitmen dalam pemberantasan korupsi yang besar. Berbagai berita tangkap tangan dan penyidangan kasus korupsi menunjukkan peningkatan pemberantasan korupsi Gambar 1.

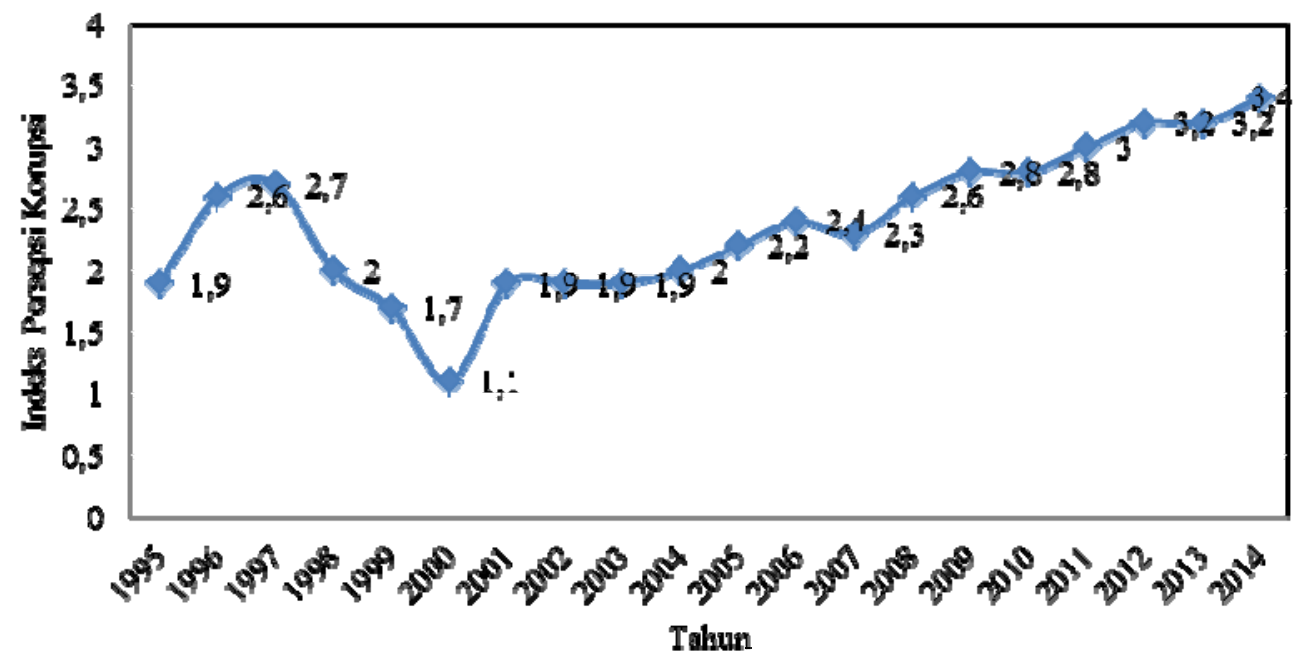

Gambar 1. Perkembangan indeks persepsi korupsi Indonesia (Sumber: Data dari Transparency International, beberapa tahun). 
Berdasarkan Gambar 1, tampaknya pemberantasan korupsi belum optimal dan masih jauh dari target rencana pembangunan nasional yang mengharapkan CPI mencapai 5 pada tahun 2015 dan mencapai 7 pada tahun 2019. Belum optimalnya pemberantasan korupsi di Asia termasuk Indonesia karena banyaknya tantangan dalam pemberantasan korupsi.

\section{Dampak Pemberantasan Korupsi terhadap Perekonomian Nasional}

Hasil simulasi menunjukkan bahwa semakin berkurangnya korupsi membuat perekonomian nasional lebih baik. Tabel 1 menunjukkan konsumsi, investasi, pengeluaran pemerintah, dan impor mengalami peningkatan dengan berhasilnya pemberantasan korupsi. Hal ini ditunjukkan dengan peningkatan PDB sebesar 3,95\% dan PDB hijau sebesar 3,94\% pada saat CPI mencapai 5. Apabila CPI mencapai 7 maka pertumbuhan ekonomi mencapai 6,8\% dan PDB hijau mencapai 6,79\%. Untuk setiap peningkatan 1 poin CPI akan meningkatkan pertumbuhan ekonomi sebesar 1,43\%. Hasil penelitian ini sedikit lebih rendah dari temuan Lambsdorff (2003 dalam Ackerman 2006) yang menunjukkan peningkatan 6 point indeks persepsi korupsi meningkatkan PDB sebesar 20\% tetapi lebih tinggi dari Mauro (1998) yang melaporkan pertumbuhan sebesar 0,25\% setiap peningkatan satu poin CPI. Namun penelitian Mauro dan Lambsdorff tersebut tidak dilakukan di Indonesia. Selain itu, setiap poin peningkatan indeks persepsi korupsi akan meningkatkan indeks pembangunan manusia sebesar 0,45, dan menurunkan pengangguran sebesar 6,59\%. Hasil tersebut memperkuat tesis bahwa korupsi mempengaruhi distribusi kesejahteraan manusia (Olken, 2006). Kecilnya peningkatan indeks pembangunan manusia per poin CPI menunjukkan korupsi menurunkan sektor yang mendukung pada kesejahteraan dan pembangunan manusia.

Keberhasilan dalam pemberantasan korupsi meningkatkan pertumbuhan ekonomi 1,43\% untuk setiap poin CPI, ceteris paribus. Hasil penelitian ini mendukung pendapat Park (2012) dan Delgado dkk (2014) yang menyatakan terdapat hubungan negatif signifikan antara korupsi dengan pertumbuhan

Tabel 1. Dampak pemberantasan korupsi terhadap perekonomian.

\begin{tabular}{|c|c|c|c|c|c|c|}
\hline \multirow[t]{2}{*}{ No } & \multirow[t]{2}{*}{ Peubah } & \multirow[t]{2}{*}{ Satuan } & \multirow{2}{*}{$\begin{array}{l}\text { Nilai } \\
\text { dasar }\end{array}$} & CPI 5 & CPI 7 & per poin CPI \\
\hline & & & & $\%$ & $\%$ & $\%$ \\
\hline 1 & Konsumsi & Rp Milyar & 3.324 .551 & 1,23 & 2,13 & 0,45 \\
\hline 2 & Investasi & Rp Milyar & 3.289 .850 & 7,28 & 12,53 & 2,62 \\
\hline 3 & Pengeluaran Pemerintah & Rp Milyar & 562.712 & 5,48 & 9,42 & 1,97 \\
\hline 4 & Ekspor & Rp Milyar & 757.115 & 0,00 & 0,00 & 0,00 \\
\hline 5 & Impor & Rp Milyar & 1.673.289 & 3,83 & 6,56 & 1,37 \\
\hline 6 & PDB & Rp Milyar & 6.260 .939 & 3,95 & 6,81 & 1,43 \\
\hline 7 & PDBHijau & Rp Milyar & 5.754 .495 & 3,94 & 6,79 & 1,43 \\
\hline 8 & PDB/capita & Rp1000/orang & 29.235 & 4,08 & 7,00 & 1,46 \\
\hline 9 & Indeks pembangunan manusia & & 0,67 & 1,25 & 2,15 & 0,45 \\
\hline 10 & Ekspor.Migas & Rp Milyar & 163.902 & 0,00 & 0,00 & 0,00 \\
\hline 11 & Ekspor Ind manufaktur & Rp Milyar & 342.207 & 0,00 & 0,00 & 0,00 \\
\hline 12 & Ekspor Prod Primer & Rp Milyar & 251.007 & 0,00 & 0,00 & 0,00 \\
\hline 13 & Impo Bahan baku & Rp Milyar & 1.280 .521 & 4,09 & 7,02 & 1,46 \\
\hline 14 & Impor Barang Modal & Rp Milyar & 297.377 & 2,81 & 4,81 & 1,00 \\
\hline 15 & Impor Barang konsumsi & Rp Milyar & 95.390 & 3,41 & 5,85 & 1,22 \\
\hline 16 & Neraca perdagangan & Rp Milyar & -916.173 & 6,99 & 11,99 & 2,50 \\
\hline 17 & Suku bunga & $\%$ & 18,72 & 0,18 & 0,30 & 0,06 \\
\hline 18 & Penawaran uang & Rp Milyar & 1.513 .564 & 1,70 & 2,92 & 0,61 \\
\hline 19 & Inflasi & $\%$ & 10,64 & 0,00 & 0,00 & 0,00 \\
\hline 20 & Nilai tukar & Rp/US\$ & 8.719 & 0,00 & 0,00 & 0,00 \\
\hline 21 & Penerimaan Non Migas & Rp Milyar & 12.821 & $-1,07$ & $-1,85$ & $-0,39$ \\
\hline 22 & Penerimaan Migas & Rp Milyar & -441.982 & 6,77 & 11,60 & 2,42 \\
\hline 23 & Pajak & Rp Milyar & 291.839 & 3,35 & 5,76 & 1,21 \\
\hline 24 & Pendapatan APBN & Rp Milyar & -133.874 & 15,15 & 25,93 & 5,39 \\
\hline 25 & Pengeluaran APBN & Rp Milyar & 339.248 & 1,68 & 2,89 & 0,61 \\
\hline 26 & Defisit anggaran & Rp Milyar & -473.122 & 5,49 & 9,41 & 1,96 \\
\hline 27 & Pengangguran & Juta orang & $-3,69$ & 18,25 & 31,42 & 6,59 \\
\hline 28 & Kemiskinan desa & Juta orang & 22,05 & 0,00 & 0,00 & 0,00 \\
\hline 29 & Kemiskinan kota & Juta orang & 11,28 & 0,00 & 0,00 & 0,00 \\
\hline 30 & Kemiskinan & Juta orang & 33,33 & 0,00 & 0,00 & 0,00 \\
\hline
\end{tabular}

Sumber : Hasil analisis. 
ekonomi. Namun penelitian ini hasilnya bertentangan dengan temuan Nawatmi (2013) yang menyimpulkan bahwa adanya korupsi meningkatkan pertumbuhan ekonomi Indonesia. Nawatmi berpandangan bahwa korupsi menjadi "oli yang meminyaki roda” pertumbuhan ekonomi Indonesia.

Penelitian ini membantah temuan Mauro (1998) bahwa korupsi tidak berdampak pada pengeluaran total pemerintah. Penelitian ini menunjukkan bahwa pemberantasan korupsi meningkatkan pengeluaran pemerintah sebesar 1,97\% untuk setiap kenaikan 1 poin CPI. Selain itu, penerimaan negara dari pajak meningkat sebesar $1,21 \%$ dan total penerimaan negara naik sebesar 5,39\% per poin CPI (coruption perception index).

Keberhasilan pemberantasan korupsi membuat penerimaan pajak meningkat sebesar 3,35\% saat CPI mencapai 5 dan sebesar $5,76 \%$ saat CPI mencapai 7. Artinya, semakin bersih pemerintahan dan usaha bisnis dari korupsi, maka penerimaan pajak semakin meningkat, begitu pula sebaliknya. Korupsi dan penyuapan pada pengumpul pajak akan membuat pajak yang terkumpul menjadi rendah. Hal ini mengindikasikan sebagian pajak diterima oleh pengumpul pajak dan tidak disetor ke negara serta pembayar pajak membayar lebih rendah dari pajak yang seharusnya.

Pemberantasan korupsi meningkatkan impor terutama impor bahan baku, impor konsumsi dan impor barang modal. Peningkatan impor yang lebih tinggi dibandingkan ekspor membuat neraca perdagangan negatif. Di pasar uang, pemberantasan korupsi membuat suku bunga meningkat dan peningkatan jumlah uang beredar. Untuk tingkat inflasi dan nilai tukar relatif stabil kurang terpengaruh dampak korupsi.

Pemberantasan korupsi membuat penerimaan migas dan non migas turun. Turunnya pendapatan tidak dapat mengkompensasi peningkatan belanja sehingga terjadi peningkatan defisit anggaran sebesar 5,49\% (CPI 5) sampai 9,41\% (CPI 7) atau $1,96 \%$ per poin CPI.

Penelitian ini sejalan temuan Kunieda dkk (2014) yang menunjukkan penurunan korupsi meningkatkan arus investasi langsung luar negeri. Temuan penelitian ini menunjukkan bahwa semakin baik nilai CPI, investasi meningkat semakin besar dimana untuk setiap peningkatan satu poin CPI meningkatkan investasi sebesar 2,62\%. Namun Tanzi dan Davoodi (1997) mengingatkan bahwa investasi publik tersebut dengan mudah dimanipulasi menggunakan kekuatan politik dan oknum birokrasi untuk kepentingan tertentu. Lebih lanjut mereka menemukan bahwa tingginya korupsi membuat rendahnya pengeluaran pemeliharaan dan operasional serta rendahnya kualitas infrastruktur. Hal ini selanjutnya membuat penurunan pertumbuhan ekonomi. Beberapa hasil temuan penelitian lain terkait dampak korupsi disajikan Tabel 2.

Penelitian ini lebih detil melihat dampak dari pemberantasan korupsi dengan mengamati perubahan pada output, penyerapan tenaga kerja dan pendapatan sektor-sektor dalam ekonomi. Perubahan-perubahan yang terjadi sebagai akibat pemberantasan korupsi disajikan Tabel 3.

Di tingkat sektor ekonomi (Tabel 3), pemberantasan korupsi meningkatkan output sektoral kecuali sektor listrik gas dan air bersih.

Tabel 2. Dampak ekonomi meningkatnya korupsi per unit indeks ${ }^{\mathrm{a}}$.

\begin{tabular}{lll}
\hline Penulis & Dampak pada & Temuan \\
\hline Mauro (1996) & Pertumbuhan PDB riil per kapita & $-0,3$ sampai -1,8\% \\
Leite dan Weidmann (1999) & Pertumbuhan PDB riil per kapita & $-0,7$ sampai -1,2\% \\
Tanzi dan Davoodi (2000) & Pertumbuhan PDB riil per kapita & $-0,6 \%$ \\
Tanzi dan Davoodi (2001) & Pertumbuhan PDB riil per kapita & -1 sampai $-1,3 \%$ \\
Mauro (1996) & Rasio investasi terhadap PDB & -1 sampai -2,8\% \\
Mauro (1998) & Rasio peng. pendidikan terhadap PDB & $-0,7$ sampai -0,9\% \\
Mauro (1998) & Rasio pengeluaran kesehatan terhadap PDB & $-0,6$ sampai -1,7\% \\
Gupta dkk (2001) & Kesenjangan pendapatan (koefisien gini) & $+0,9$ sampai +2,1 gini poin \\
Gupta dkk (2001) & Pertumbuhan pendapatan si miskin & -2 sampai -10\% \\
Ghura (1998) & Rasio penerimaan pajak terhadap PDB & -1 sampai -2,9\% \\
Tanzi dan Davoodi (2000) & Rasio penerimaan pemerintah pada PDB & $-0,1$ sampai -4,5\% \\
Gupta dkk (2001) & Rasio pengeluaran pemerintah pada PDB & $+1 \%$ \\
Gupta dkk (2001) & Tingkat kematian anak-anak & $+1,1$ sampai 2,7 kematian per $\quad 1000$ \\
& & kelahiran \\
Gupta dkk (2000) & Tingkat putus pendidikan dasar & $+1,4$ sampai +4,8\% \\
Tanzi dan Davoodi (1997) & Rasio investasi public terhadap PDB & $+0,5 \%$ \\
Tanzi dan Davoodi (1997) & Persen jalan yang baik & $-2,2$ sampai -3,9\% \\
\hline
\end{tabular}

Sumber: diekstrak dari Tranparency International (2001 dalam Vazquez dkk, 2007)

$\mathrm{a}=$ korupsi mengukur dengan skala 0 (sangat bersih) sampai 10 (sangat korup) 
Tabel 3. Dampak pemberantasan korupsi terhadap output, tenaga kerja dan pendapatan.

\begin{tabular}{|c|c|c|c|c|c|c|}
\hline No & Peubah & Satuan & Nilai dasar & CPI $5 \%$ & CPI $7 \%$ & Per poin CPI \\
\hline & Output & & & & & \\
\hline 1 & Pertanian & Rp Milyar & 668.371 & 2,71 & 4,66 & 0,98 \\
\hline 2 & Kehutanan & Rp Milyar & 40.760 & 2,30 & 3,97 & 0,83 \\
\hline 3 & Tambang & Rp Milyar & 498.385 & 3,02 & 5,21 & 1,09 \\
\hline 4 & Industri & Rp Milyar & 1.174 .542 & 2,37 & 4,08 & 0,86 \\
\hline 5 & Listrik gas air & Rp Milyar & 23.089 & $-0,03$ & $-0,04$ & $-0,01$ \\
\hline 6 & Bangunan & Rp Milyar & 976.273 & 5,27 & 9,08 & 1,90 \\
\hline 7 & Perdagangan hotel restoran & Rp Milyar & 618.560 & 2,53 & 4,36 & 0,91 \\
\hline 8 & Transportasi & Rp Milyar & 200.365 & 1,41 & 2,43 & 0,51 \\
\hline 9 & Keuangan & Rp Milyar & 319.476 & 2,59 & 4,46 & 0,94 \\
\hline 10 & Jasa & Rp Milyar & 4.103.353 & 0,27 & 0,46 & 0,10 \\
\hline \multirow[t]{2}{*}{11} & Total & Rp Milyar & 8.623.176 & 1,75 & 3,02 & 0,63 \\
\hline & Tenaga kerja & & & & & \\
\hline 1 & Pertanian & 1000 orang & 43.999 & 0,68 & 1,17 & 0,24 \\
\hline 2 & Kehutanan & 1000 orang & 851,93 & 0,99 & 1,70 & 0,36 \\
\hline 3 & Tambang & 1000 orang & 1.319 & 2,27 & 3,87 & 0,80 \\
\hline 4 & Industri & 1000 orang & 13.802 & 1,02 & 1,75 & 0,37 \\
\hline 5 & Listrik gas air & 1000 orang & 202,91 & 0,28 & 0,48 & 0,10 \\
\hline 6 & Bangunan & 1000 orang & 5.700 & 1,75 & 3,02 & 0,63 \\
\hline 7 & Perdagangan hotel restoran & 1000 orang & 22.680 & 1,51 & 2,60 & 0,54 \\
\hline 8 & Transportasi & 1000 orang & 5.464 & 1,15 & 1,98 & 0,41 \\
\hline 9 & Keuangan & 1000 orang & 2.064 & 3,10 & 5,33 & 1,11 \\
\hline 10 & Jasa & 1000 orang & 2.440 .412 & 0,01 & 0,01 & 0,00 \\
\hline \multirow[t]{2}{*}{11} & Total & 1000 orang & 2.536 .495 & 0,05 & 0,09 & 0,02 \\
\hline & Pendapatan Sektor & & & & & \\
\hline 1 & Pertanian & Rp ribu & 17.666 & 2,88 & 4,96 & 1,04 \\
\hline 2 & Kehutanan & Rp ribu & 40.106 & 0,64 & 1,11 & 0,23 \\
\hline 3 & Tambang & Rp ribu & 374.640 & 1,35 & 2,32 & 0,49 \\
\hline 4 & Industri & Rp ribu & 62.809 & 0,86 & 1,47 & 0,30 \\
\hline 5 & Listrik gas air & Rp ribu & 138.414 & 1,02 & 1,75 & 0,37 \\
\hline 6 & Bangunan & Rp ribu & 107.647 & 3,98 & 6,85 & 1,44 \\
\hline 7 & Perdagangan hotel restoran & Rp ribu & 27.281 & 1,51 & 2,60 & 0,55 \\
\hline 8 & Transportasi & Rp ribu & 56.365 & 2,65 & 4,57 & 0,96 \\
\hline 9 & Keuangan & Rp ribu & 28.212 & $-36,79$ & $-63,35$ & $-13,28$ \\
\hline 10 & Jasa & Rp ribu & 26.442 & 1,58 & 2,72 & 0,57 \\
\hline 11 & Total & Rp Milyar & 8.331.337 & 1,70 & 2,92 & 0,61 \\
\hline
\end{tabular}

Sumber : Hasil analisis.

Tabel 4. Dampak pemberantasan korupsi terhadap emisi karbon.

\begin{tabular}{|c|c|c|c|c|c|c|}
\hline No & Peubah & Satuan & Nilai dasar & CPI $5 \%$ & CPI $7 \%$ & per poin CPI \\
\hline \multirow[t]{12}{*}{1} & \multicolumn{6}{|l|}{ Emisi karbon dari sektor } \\
\hline & Kehutanan & Ton $\mathrm{CO}_{2}$ & -289.925 .000 & $-0,04$ & $-0,08$ & $-0,02$ \\
\hline & Pertanian & Ton $\mathrm{CO}_{2}$ & 137.078.229 & 2,88 & 4,96 & 1,04 \\
\hline & Tambang & Ton $\mathrm{CO}_{2}$ & 142.856.092 & 0,32 & 0,56 & 0,12 \\
\hline & Industri & Ton $\mathrm{CO}_{2}$ & 762.201 .411 & 0,79 & 1,35 & 0,28 \\
\hline & Listrik gas air & Ton $\mathrm{CO}_{2}$ & 22.901.939 & $-0,06$ & $-0,10$ & $-0,02$ \\
\hline & Bangunan & Ton $\mathrm{CO}_{2}$ & 117.734.694 & 3,53 & 6,08 & 1,27 \\
\hline & Perdagangan, hotel, restoran & Ton $\mathrm{CO}_{2}$ & 135.725.652 & 3,04 & 5,23 & 1,10 \\
\hline & Transportasi & Ton $\mathrm{CO}_{2}$ & 49.460 .235 & 2,40 & 4,13 & 0,87 \\
\hline & Keuangan & Ton $\mathrm{CO}_{2}$ & 33.476.125 & 4,16 & 7,13 & 1,49 \\
\hline & Jasa & Ton $\mathrm{CO}_{2}$ & 46.350 .375 & 0,86 & 1,47 & 0,31 \\
\hline & Total emisi karbon & Ton $\mathrm{CO}_{2}$ & 1.447 .490 .000 & 1,50 & 2,57 & 0,54 \\
\hline 2 & Emisi/kapita & Ton $\mathrm{CO}_{2}$ /orang & 1,78 & 1,47 & 2,52 & 0,53 \\
\hline \multirow[t]{4}{*}{3} & \multicolumn{6}{|c|}{ Emisi karbon dari deforestasi hutan untuk } \\
\hline & Kebun sawit & 1000 ton $\mathrm{CO}_{2}$ & 161.648 & $-0,03$ & $-0,05$ & $-0,01$ \\
\hline & Kebun karet & 1000 ton $\mathrm{CO}_{2}$ & 3.531 & 0,06 & 0,08 & 0,01 \\
\hline & Tanaman padi & 1000 ton $\mathrm{CO}_{2}$ & 85.307 & $-0,01$ & $-0,01$ & 0,00 \\
\hline 4 & Emisi degradasi hutan & 1000 ton $\mathrm{CO}_{2}$ & -764.886 & 0,14 & 0,24 & 0,05 \\
\hline 5 & Emiter & 1000 ton $\mathrm{CO}_{2}$ & 1.445 .650 .000 & 1,50 & 2,58 & 0,54 \\
\hline
\end{tabular}

Sumber : Hasil analisis. 
Pemberantasan korupsi meningkatkan penyerapan tenaga kerja dan pendapatan sektoral kecuali pendapatan sektor keuangan yang turun 36,79\% (CPI 5) sampai dengan 63,35\% (CPI 7) atau turun $13,28 \%$ per peningkatan poin CPI. Peningkatan penyerapan tenaga kerja sektoral menurunkan pengangguran sebesar 18,25\% (CPI 5) sampai dengan 31,42\% (CPI 7) atau 6,59\% per poin CPI. Namun pemberantasan korupsi belum berdampak besar pada penurunan kemiskinan desa dan kota.

Tabel 5. Dampak pemberantasan korupsi terhadap kinerja sektor kehutanan.

\begin{tabular}{|c|c|c|c|c|c|c|}
\hline No & Peubah & Satuan & Nilai dasar & CPI $5 \%$ & CPI $7 \%$ & Per poin CPI \\
\hline 1 & Jatah tebang tahunan & Juta $\mathrm{m}^{3}$ & 11,25 & 0,01 & 0,01 & 0,00 \\
\hline \multirow[t]{6}{*}{2} & Produksi kayu & & & & & \\
\hline & Bulat & $1000 \mathrm{~m}^{3}$ & 54.844 & $-0,03$ & $-0,06$ & $-0,01$ \\
\hline & Gergajian & $1000 \mathrm{~m}^{3}$ & 6.157 & 0,00 & 0,00 & 0,00 \\
\hline & Lapis & $1000 \mathrm{~m}^{3}$ & 7.085 & $-0,01$ & $-0,01$ & 0,00 \\
\hline & Pulp & 1000 ton & 3.454 & $-0,12$ & $-0,17$ & $-0,03$ \\
\hline & Papan panel & $1000 \mathrm{~m}^{3}$ & 7.857 & $-0,01$ & $-0,01$ & 0,00 \\
\hline 3 & Penerimaan kehutanan & Rp Milyar & 3.448 & $-0,06$ & $-0,09$ & $-0,01$ \\
\hline 4 & Dana reboisasi & Rp Milyar & 2.286 & $-0,04$ & $-0,09$ & $-0,02$ \\
\hline 5 & Harga kayu bulat & $\mathrm{Rp} / \mathrm{m}^{3}$ & 1.208 .892 & 0,00 & 0,00 & 0,00 \\
\hline 6 & Penawaran log & $1000 \mathrm{~m}^{3}$ & 54.800 & 0,00 & 0,00 & 0,00 \\
\hline \multirow[t]{5}{*}{7} & Permintaan log untuk industri $\mathrm{k}$ & & & & & \\
\hline & Gergajian & $1000 \mathrm{~m}^{3}$ & 11.145 & 0,00 & 0,00 & 0,00 \\
\hline & Lapis & $1000 \mathrm{~m}^{3}$ & 14.170 & $-0,01$ & $-0,01$ & 0,00 \\
\hline & Pulp & $1000 \mathrm{~m}^{3}$ & 13.816 & $-0,11$ & $-0,19$ & $-0,04$ \\
\hline & Papan panel & $1000 \mathrm{~m}^{3}$ & 15.714 & $-0,01$ & $-0,02$ & 0,00 \\
\hline 8 & Penawaran kayu ilegal & $1000 \mathrm{~m}^{3}$ & 28.743 & $-0,06$ & $-0,09$ & $-0,02$ \\
\hline \multirow[t]{13}{*}{9} & Deforestasi hutan untuk & & & & & \\
\hline & HTI & 1000 ha & 408,87 & $-0,13$ & $-0,22$ & $-0,04$ \\
\hline & Sawit rakyat & 1000 ha & 153,49 & $-0,07$ & $-0,13$ & $-0,03$ \\
\hline & Sawit negara & 1000 ha & 15,01 & 0,00 & 0,00 & 0,00 \\
\hline & Sawit swasta & 1000 ha & 189,64 & 0,00 & 0,00 & 0,00 \\
\hline & Sawit & 1000 ha & 358,14 & $-0,03$ & $-0,05$ & $-0,01$ \\
\hline & Karet rakyat & 1000 ha & 17,52 & 0,06 & 0,10 & 0,02 \\
\hline & Karet negara & 1000 ha & $-1,09$ & 0,07 & 0,13 & 0,03 \\
\hline & Karet swasta & 1000 ha & 2,25 & 0,04 & 0,06 & 0,01 \\
\hline & Karet & 1000 ha & 18,68 & 0,05 & 0,09 & 0,02 \\
\hline & Padi sawah & 1000 ha & 126,32 & $-0,01$ & $-0,01$ & 0,00 \\
\hline & Padi lading & 1000 ha & 0,35 & 0,00 & 0,00 & 0,00 \\
\hline & Padi & 1000 ha & 126,66 & $-0,01$ & $-0,01$ & 0,00 \\
\hline 10 & Deforestasi hutan & 1000 ha & 912,35 & $-0,07$ & $-0,12$ & $-0,02$ \\
\hline 11 & Degradasi hutan & 1000 ha & -1.534 & 0,13 & 0,26 & 0,07 \\
\hline \multirow[t]{5}{*}{12} & Luas kebakaran hutan & & & & & \\
\hline & Sumatera & 1000 ha & 753,51 & 0,00 & 0,00 & 0,00 \\
\hline & Kalimantan & 1000 ha & 903,51 & 0,00 & 0,00 & 0,00 \\
\hline & Papua & 1000 ha & 152,13 & 0,00 & 0,00 & 0,00 \\
\hline & Indonesia & 1000 ha & 1.809 & 0,00 & 0,00 & 0,00 \\
\hline \multirow[t]{5}{*}{13} & Degradasi lahan gambut & & & & & \\
\hline & Sumater & 1000 ha & $-75,71$ & 0,00 & 0,00 & 0,00 \\
\hline & Kalimantan & 1000 ha & $-33,07$ & 0,00 & 0,00 & 0,00 \\
\hline & Papua & 1000 ha & $-121,87$ & 0,00 & 0,00 & 0,00 \\
\hline & Indonesia & 1000 ha & $-230,65$ & 0,00 & 0,00 & 0,00 \\
\hline \multirow[t]{5}{*}{14} & Deforestasi hutan rawa gambut & & & & & \\
\hline & Sumatera & 1000 ha & $-118,95$ & 0,00 & 0,00 & 0,00 \\
\hline & Kalimantan & 1000 ha & $-99,93$ & 0,00 & 0,00 & 0,00 \\
\hline & Papua & 1000 ha & $-69,60$ & 0,00 & 0,00 & 0,00 \\
\hline & Indonesia & 1000 ha & $-288,48$ & 0,00 & 0,00 & 0,00 \\
\hline \multirow[t]{5}{*}{15} & Kebakaran gambut & & & & & \\
\hline & Sumatera & 1000 ha & 172,66 & 0,00 & 0,00 & 0,00 \\
\hline & Kalimantan & 1000 ha & 248,98 & 0,00 & 0,00 & 0,00 \\
\hline & Papua & 1000 ha & 15,13 & 0,00 & 0,00 & 0,00 \\
\hline & Indonesia & 1000 ha & 436,76 & 0,00 & 0,00 & 0,00 \\
\hline
\end{tabular}

Sumber : Hasil analisis. 


\section{Dampak Pemberantasan Korupsi terhadap Emisi Karbon (Lingkungan)}

Penelitian ini membuktikan pula adanya dampak pemberantasan korupsi terhadap emisi karbon atau perubahan iklim/lingkungan (Tabel 4). Aktivitas ekonomi yang meningkat (Tabel 1 dan 3) membuat emisi karbon yang dihasilkan setiap sektor ekonomi juga meningkat yan selanjutnya menyebabkan perubahan iklim (kerusakan lingkungan).

Tabel 4 menunjukkan bahwa pemberantasan korupsi meningkatkan emisi karbon 1,50\% (CPI 5) dan 2,57\% (CPI 7) atau sebesar $0,54 \%$ tiap poin CPI. Hasil penelitian ini didukung hasil Cole (2007) yang menunjukkan hubungan korupsi dengan tingkat emisi adalah negatif. Penurunan tingkat korupsi diperkirakan meningkatnya aktivitas sektor ekonomi (Tabel 4) sehingga emisi karbon meningkat kecuali sektor listrik, gas dan air yang turun sebesar $0,02 \%$ setiap poin CPI.

Untuk mengatasi peningkatan emisi karbon akibat peningkatan aktivitas ekonomi, diperlukan efisiensi produksi yang menghasilkan emisi karbon minimal. Sektor ekonomi pengemisi karbon harus mengembangkan mekanisme agar emisi karbonnya rendah. Pembangunan ekonomi diselaraskan dengan lingkungan dengan ekonomi rendah karbon (Bumpus dan Liverman, 2008; Mitchell, 2009; Lovell dan Liverman, 2010; Bridge, 2010; Buizer dkk, 2014: Zimmer dkk, 2015). Mekanisme pendanaan untuk efisiensi karbon ini telah dikembangkan namun penelitian Haryanto (2015) menunjukkan kurang efektif dan tidak menarik.

\section{Dampak Pemberantasan Korupsi terhadap Kinerja Sektor Kehutanan}

Pemberantasan korupsi berdampak pula pada kinerja sektor kehutanan (Tabel 5). Tabel 5 menunjukkan bahwa produksi kayu bulat dan pulp turun sedangkan produksi kayu gergajian, kayu lapis dan papan panel tidak banyak berubah.

Pada Tabel 5, pemberantasan korupsi sedikit menurunkan kinerja industri primer kehutanan dimana produksi kayu bulat, kayu gergajian, kayu lapis, pulp dan papan panel mengalami sedikit penurunan. Penurunan produksi kayu menurunkan permintaan kayu bulat untuk industri primer kehutanan. Dampak lainnya adalah turunnya penerimaan dana reboisasi yang diikuti turunnya penerimaan sektor kehutanan sebagai akibat keberhasilan pemberantasan korupsi. Namun demikian penurunan kinerja industri kehutanan masih di bawah satu persen sehingga keberhasilan pemberantasan korupsi masih berdampak positif.

Tingkat deforestasi dan degradasi hutan mengalami penurunan baik deforestasi untuk HTI, perkebunan sawit rakyat, dan padi sawah. Namun, deforestasi untuk kebun karet rakyat, negara dan swasta mengalami sedikit peningkatan (di bawah 0,5\%). Penelitian ini sejalan dengan Galinato dan Galinato (2013) yang menunjukkan adanya keterkaitan antara korupsi dengan illegal logging dan deforestasi. Penelitian ini menunjukkan bahwa dampak pemberantasan korupsi berbeda-beda untuk setiap penyebab deforestasi (HTI, sawit rakyat, sawit negara, sawit swasta, karet rakyat, karet negara, karet swasta, tanaman pangan, dan gambut). Penelitian ini menunjukkan pula bahwa untuk kebakaran hutan dan lahan gambut kondisinya relatif tidak ditentukan oleh pemberantasan korupsi. Penelitian ini lebih jauh dari Barbier dkk (2005) yang menemukan peningkatan korupsi meningkatkan konversi lahan dan deforestasi hutan tropis tetapi tanpa memerinci perilaku penyebab deforestasinya.

\section{KESIMPULAN}

Upaya pemberantasan korupsi di Indonesia sudah dilakukan sejak lama namun hasilnya belum optimal. Keberhasilan pemberantasan korupsi membuat kondisi perekonomian makro lebih baik, meningkatkan emisi karbon (lingkungan) dan meningkatkan kinerja sektor kehutanan. Tingkat korupsi yang rendah meningkatkan pertumbuhan ekonomi, investasi, pengeluaran pemerintah, penerimaan pajak, mengurangi pengangguran tetapi tidak mempengaruhi jumlah penduduk miskin.

Pemberantasan korupsi meningkatkan aktivitas sektor-sektor ekonomi yang selanjutnya meningkatkan emisi karbon yang dihasilkan sebagai penyebab perubahan iklim, sedangkan kinerja industri primer kehutanan dan dana reboisasi turun dengan pemberantasan korupsi, namun secara keseluruhan sektor kehutanan diuntungkan dengan pemberantasan korupsi.

Upaya pemberantasan korupsi seyogyanya terus dilakukan karena memberikan dampak yang lebih baik pada kondisi perekonomian dan sektor kehutanan. Peran sektor kehutanan dalam menyerap emisi karbon perlu ditingkatkan untuk menyerap emisi karbon. Peningkatan penyerapan emisi karbon dilakukan dengan penanaman hutan, pencegahan deforestasi degradasi hutan dan pencegahan kebakaran hutan.

\section{DAFTAR PUSTAKA}

Ackerman, S.R., 2006. International Handbook on The Economics of Corruption. Edward Elgar. London. 
Aidt, T., 2009. Corruption Institutions and Economic Development. Oxford Review of Economic Policy, 25(2):271-292.

Amacher, G.S., 2006. Corruption: A Challenge for Economists Interested in Forest Policy Design. Journal of Forest Economics 12:85-89.

Amacher, G., Ollikainen, M., dan Koskela, E., 2012. Corruption and Forest Concessions. Journal of Environmental Economics and Management, 63:92-104.

Andrei, T., Matei, A., dan Rosca, I., 2009. The Corruption: An Economic and Social Analysis. Editura Economica. Bucharest.

Barbier, E.B., Damania, R., dan Leonard, D., 2005. Corruption, Trade and Resource Conversion. Journal of Environmental Economics and Management, 50:276-299.

Bhattacharyya, S., dan Hodler, R., 2010. Natural Resources, Democracy and Corruption. European Economic Review, 54:608-621.

Bloom, P., 2010. How do Moral Change?. Nature, 464(25):490.

Bridge, G., 2010. Resource Geographies 1: Making Carbon Economies, Old and New. Progress in Human Geography, 35(6):820-834.

Buizer, M., Humphreys, D., dan de Jong, W., 2014. Climate Change and Deforestation: The Evolution of an Intersecting Policy Domain. Environmental Science and Policy, 35:1-11.

Bumpus, A., dan Liverman, D., 2008. Accumulation by Decarbonisation and The Governance of Carbon Offsets. Economic Geography, 84:127-155.

Cole, M.A., 2007. Corruption, Income and The Environment: An Empirical Analysis. Ecological Economics 62:637-647.

Delgado, M.S., McCloud, N., dan Kumbhakar, S.C., 2014. A Generalized Empirical Model of Corruption, Foreign Direct Investment, and Growth. Journal of Macroeconomics, 42:298316.

Dermawan, A., Petkova, E., Sinaga, A., Muhajir, M., dan Indriatmoko, Y., 2011. Preventing The Risk of Corruption in REDD+ in Indonesia. Working Paper 80. Cifor. Bogor.

Dreher, A., Kotsogiannie, C., dan McCorriston, S., 2007. Corruption Around The World: Evidence from A Structural Model. Journal of Comparative Economics, 35:443-466.

Galinato, G.I., dan Galinato, S.P., 2013. The ShortRun and Long-Run Effects of Corruption Control and Political Stability on Forest Cover. Ecological Economics, 89:153-161.

Goel, R.K., dan Nelson, M.A., 2010. Causes of Corruption: History, Geography and
Government. Journal of Policy Modeling, 32:433-447.

Halkos, G.E., dan Tzeremes, N.G., 2014. Public Sector Transparency and Countries Environmental Performance: A Nonparametric Anaysis. Resource and Energy Economics, 38:19-37.

Haryanto, J.T., 2015. Specific Allocation Fund for Energy Efficiency to Increase Quality of The Environment in Indonesia. Jurnal Manusia dan Lingkungan, 22(1):129-134.

Kunieda, T., Okada, K., dan Shibata, A., 2014. Corruption, Capital Account Liberazation, and Economic Growth: Theory and Evidence. International Economics, 139: 80-108.

Lambsdorff, J.G., 2007. The Institutional Economics of Corruption and Reform: Theory, Evidence and Policy. Cambridge University Press. Cambridge.

Lee, J.H., Sigmund, K., Diecmann, U., dan Iwasa, Y., 2015. Game of Corruption: How to Suppress Illegal Logging. Journal of Theoritical Biology, 367:1-13.

Leitao, A., 2010. Corruption and The Environmental Kuznets Curve: Empirical Evidence for Sulfur. Ecological Economics, 69:2191-2201.

Lovell, H., dan Liverman, D., 2010. Understanding Carbon Offset Technologies. New Political Economy, 15(2):255-274.

Mauro, P., 1998. Corruption and The Composition of Government Expenditure. Journal of Public Economics, 69(2):263-279.

Mitchell, T., 2009. Carbon Democracy. Economy and Society, 28(3):399-432.

Nawatmi, S., 2013. Korupsi dan Pertumbuhan Ekonomi: Studi Empiris 33 Provinsi di Indonesia. Dinamika Akuntansi, Keuangan dan Perbankan, 2(1):66-81.

Olken, B.A., 2006. Corruption and The Cost of Redistribution: Micro Evidence from Indonesia. Journal of Public Economics, 90:853-870.

Olken, B.A., dan Pande, R., 2012. Corruption in Developing Countries. Annual Review of Economics, 4:479-509.

Park, J., 2012. Corruption, Soundness of The Banking Sector, and Economic Growth: A Cross-Country Study. Journal of International Money and Finance, 31:907-927.

Pellegrini, L., 2011. Corruption, Development and The Environment. Springer. London. $160 \mathrm{Hal}$.

Rock, M.T., dan Bonnett, H., 2004. The Comparative Politics of Corruption: Accounting for The East Asian Paradox in Empirical Studies of Corruption Growth and 
Investment. World Development, 32(6):9991017.

Shafiq, M.N., 2015. Aspects of Moral Change in India, 1990-2006: Evidence from Public Attitudes toward Tax Evasion and Bribery. World Development, 68:136-148.

Sims, R.L., Gong, B., dan Ruppel, C.P., 2012. A Contingency Theory of Corruption: The Effect of Human Development and National Culture. The Social Science Journal, 49: 90-97.

Sloan, S., 2014. Indonesia's Moratorium on New Forest Licenses: An Update. Land Use Policy, 38:37-40.

Sundstrom, A., 2015. Covenants with Broken Swords: Corruption and Law Enforcement in Governance of The Commons. Global Environmental Change, 31:253-262.

Tanzi, V., dan Davoodi, H., 1997. Corruption, Public Investment and Growth. IMF working paper series WP/97/139. International Monetary Fund. Washington, DC.
Umar, H., 2011. Menghitung Kembali Dampak Korupsi. Jurnal Bisnis dan Manajemen, 7(1):24-31.

Varvarigos, D., dan Arsenis, P., 2015. Corruption, Fertility, and Human Capital. Journal of Economic Behavior and Organization, 109:145-162.

Vazquez, J.M., Granado, J.A., dan Boex, J., 2007. Fighting Corruption in The Public Sector. Elsevier. Oxford.

Vial, V., dan Hanoteau., 2010. Corruption, Manufacturing Plant Growth, and The Asian Paradox: Indonesian Evidence. World Development, 38(5):693-705.

Walter, M., 2013. The Impact of Corruption on Climate Change: Threatening Emissions Trading Mechanisms?. Environmental Development, 7:128-138.

Zimmer, A., Jakob, M., dan Steckel, J.C., 2015. What Motivates Vietnam to Strive for a LowCarbon Economy? On The Drivers of Climate Policy in a Developing Country. Energy for Sustainable Development, 24:19-32. 